\title{
Optimization of Drying Conditions to Preserve Gingerol in Ginger
}

\section{Bilal Hafeez ${ }^{1}$, Husnain Azam², Ijaz Ul Haq ${ }^{3}$, Nida Firdous ${ }^{4 *}$, Muhammad Muddassir ${ }^{3}$, Haroon Saleem ${ }^{3}$ and Muhammad Usman ${ }^{3}$}

${ }^{1}$ National Institute of Food Science and Technology, University of Agriculture, Faisalabad, Pakistan

${ }^{2}$ Institute of Home and Food Sciences, Government College University Faisalabad, Pakistan

${ }^{3}$ Department of Food Engineering, University of Agriculture, Faisalabad, Pakistan. ${ }^{4}$ Punjab Food Authority, Punjab, Pakistan

*Corresponding Author: Nida Firdous, Punjab Food Authority, Punjab, Pakistan.
Received: April 26, 2021

Published: June 24, 2021

(C) All rights are reserved by Nida Firdous., et al.

\begin{abstract}
Ginger is considered a medicinal herb for long years ago due to the presence of various bioactive compounds like gingerol. Gingerol is further categorized as 6-gingerol, 8-gingerol, 10-gingerol. Ginger is used as spices and in dietary supplements. Ginger rhizome is also used to provide flavor in savory dishes like sweets, biscuits, cakes, curries, and beverages such as ginger wine, ginger beer, and soft drinks. It has antioxidants and anti-inflammatory properties. Different processing methods are being used which hadan enormous effect on the quality of these bioactive components in ginger and drying is one of them. The objective of the study was to find the optimum drying condition in terms of maximum nutrients preserve in ginger. In the first phase, ginger was dried through various drying techniques i.e., sun drying, oven drying, microwave having different treatments. Extraction was done through the Soxhlet extraction method of dried ginger. After extraction, the equal weight of 6-gingerol, 8-gingerol, and 10-gingerol was prepared and analyzed on high-performance liquid chromatography (HPLC) to check the concentration of gingerols preserve. The obtained data were subjected to statistical analysis to check the significance level. It was concluded that the optimum drying condition was oven drying at $70^{\circ} \mathrm{C}$ in which maximum gingerol preserve. The quantity of 6-gingerol, 8-gingerol, 10 -gingerol were $2.61 \mathrm{mg} / \mathrm{g}, 2.27 \mathrm{mg} / \mathrm{g}$, $2.44 \mathrm{mg} / \mathrm{g}$, respectively at optimum drying condition.
\end{abstract}

Keywords: Medicinal; Gingerol; Dietary Supplements; Rhizome; Sun-drying; Microwave

\section{Introduction}

Ginger (Zingiber Officinale Roscoe), a rhizome of the plant is one of the most precious herbs as medicine in the world. It belongs to the Zingiberaceae family. It is also used as spices to enhance taste and flavor for making food products delicious [15]. In ancient times, fresh ginger has been used as food, medicine, and dietary supplements. Ginger has many functional health benefits such as food antioxidants, and good food for curing different diseases [5].
The rhizome ginger is a rich source of vitamins, minerals, carbohydrates, other proximate compositions, and bioactive compounds which have to be efficient to care for different diseases such as inflammation [4]. The health-improving mode of ginger is indicated that it is a good source of phytochemicals that occur in ginger naturally. They protect humans from various disorders that are related to inflammation and oxidative stress [14]. Oxidative stress is colligated to an imbalance between the antioxidant's biological defense 
system and the production of reactive oxygen and free radicals. The uncontrolled production of free radicals will be initiated and the chain reaction of oxidation will be propagated and tends to the development of inflammation [12].

Fresh ginger has high contents of moisture, so it is a highly perishable food. Because of high moisture, it can cause spoilage such as enzymatic reaction and other unfavorable changes such as shelf life of the product [2]. Different processing techniques are being used to preserve ginger and these techniques have a great effect on the quality of bioactive compounds that are present in ginger and drying is one of them [10]. Drying is an old technique to preserve different food items in which the amount of water contents reduces and enhances the shelf life of food. Some drying methods are shade drying, sun drying, freeze-drying, oven drying, vacuum drying, and microwave, etc. [9].

Despite, the increase in the shelf life of ginger, drying techniques are also telling about the main factor such as rhizomes, lipids, and other phenolic compounds that tend to alter of natural active substance present in ginger [7]. Since many complex reactions occur during the processing of drying, natural phytochemicals present in ginger degrade and change the final quality of ginger and making new components of phytochemicals that have a good therapeutic effect in dried ginger than fresh ginger when compared to each other. The Research work that had been conducted on leaves of green tea reported that the processing of drying increases the value of the final product as compared to the fresh product in terms of vitamin C, the activity of antioxidants, contents of phytochemicals or active substances [10].

Gingerol is an active component of ginger. It is further divided into three categories i.e., 6-gingerol, 8-gingerol, 10-gingerol [15]. They have many pharmacological effects. In the Series of gingerol, 6-gingerol has a more convertible mechanism of kinetics in extraction by using ethanol [3]. In fresh ginger, there is the percentage of bioactive compounds like gingerol is $96 \%$ - $97 \%$, and shogaol is $3 \%$ - 4\%. However, the gingerol is changed over into shogaol [pungent constituents of ginger similar in chemical structure to gingerol] when applying heat. It is because of thermal degradation as at high temperatures they are not stable [8].

Different extraction methods can be used to get oils or extract from the rhizome of ginger. The old extraction technique includes steam distillation, hydro-distillation, maceration, Soxhlet extraction, empyreumatic distillation. The latest and new technologies are environmentally friendly i.e. supercritical fluid extraction and subcritical extraction methods although these extraction methods can be performed by use of water for extraction purposes. The best extraction method is supercritical fluid extraction due to higher yield and obtains the targeted components, but the disadvantage is that it is costly [13]. For analysis of 6-gingerol, 8-gingerol, 10-gingerol, there are many different modern techniques like highperformance liquid chromatography (HPLC), gas chromatography (Separation process used to separate compounds from a mixture), and mass spectrometry (GC-MS) in which gingerol is quantifying [11].

\section{Aim of the Study}

Therefore, this research work aims to determine the natural active constituents of fresh and dried ginger as directed to different treatments of drying. This research work has planned to meet the following objective: To find the optimum drying condition in terms of maximizing the gingerol preservation in ginger.

\section{Materials and Methods}

\section{Procurement of raw material}

The research work was done in the National Institute of Food Science and Technology in collaboration with the Department of Structure and Environmental Engineering, University of Agriculture, Faisalabad. For Sampling, the ginger rhizome was procured from the local market of Faisalabad. Chemicals were purchased from the authenticated suppliers in the Faisalabad market.

Drying of ginger

Ginger was dried under different drying conditions, sun drying, oven drying, microwave following procedures as described by An., et al. [1] and Mustafa [9]. These methods are briefly described below.

\section{Sun drying}

Sun rays were used as a source of energy for drying, during January and February following the method as stated by Mustafa [9]. Sun-drying was used to reduce the moisture contents from ginger. Ginger was washed, sliced, and placed into the solar tunnel dryer for 2 days. After two days, the dried ginger was transferred into a desiccator to avoid moisture contents. Then the dried ginger was 
grinded (splitting into small particles) into the grinder and converted into powder form.

\section{Oven drying}

Ginger was washed, sliced, and placed into a drying oven to remove the moisture contents. In oven drying, ginger was dried under different ranges of temperature $\left(60^{\circ} \mathrm{C}, 70^{\circ} \mathrm{C}, 80^{\circ} \mathrm{C}\right.$, and $\left.90^{\circ} \mathrm{C}\right)$ at a different time $(8,7,6.5$, and 6 hours) respectively following procedure as described by Mustafa [9]. After drying of ginger (reduction in moisture content), the dried ginger was packed into the plastic bags and placed into a desiccator to avoid moisture.

\section{Microwave drying}

Microwave drying is used to remove the moisture contents in ginger. Ginger was washed, sliced, and placed into the microwave oven. Ginger rhizome was dried through microwave under different conditions of power (100W, 200W, 300W, 450W, 600W, 700W, and $800 \mathrm{~W})$ at a different time $(180,60,45,35,20,15$, and $12 \mathrm{~min}$ utes) respectively, following the given method described by An., et al. [1]. After drying of ginger (reduction in moisture content), the dried ginger was packed into the plastic bags and placed into a desiccator to avoid moisture.

Treatment plan - at different drying techniques

\begin{tabular}{|l|c|c|c|}
\hline Conditions & Treatments & $\begin{array}{c}\text { Temperature } \\
\text { ('C Degree } \\
\text { Celsius) }\end{array}$ & Power \\
\hline Controlled & $\mathrm{T}_{0}$ & - & - \\
\hline Sun drying & $\mathrm{T}_{1}$ & - & - \\
\hline Oven drying & $\mathrm{T}_{2}$ & $60^{\circ} \mathrm{C}$ & - \\
\hline & $\mathrm{T}_{3}$ & $70^{\circ} \mathrm{C}$ & - \\
\hline & $\mathrm{T}_{4}$ & $80^{\circ} \mathrm{C}$ & - \\
\hline & $\mathrm{T}_{5}$ & $90^{\circ} \mathrm{C}$ & - \\
\hline Microwave & $\mathrm{T}_{6}$ & - & $100 \mathrm{~W}$ \\
\hline & $\mathrm{T}_{7}$ & - & $200 \mathrm{~W}$ \\
\hline & $\mathrm{T}_{8}$ & - & $300 \mathrm{~W}$ \\
\hline & $\mathrm{T}_{9}$ & - & $450 \mathrm{~W}$ \\
\hline & $\mathrm{T}_{10}$ & - & $600 \mathrm{~W}$ \\
\hline & $\mathrm{T}_{11}$ & - & $700 \mathrm{~W}$ \\
\hline & $\mathrm{T}_{12}$ & - & $800 \mathrm{~W}$ \\
\hline
\end{tabular}

Table 1

\section{Extraction of ginger}

Extraction was done by the Soxhlet extraction technique using ethanol/methanol following the method described by Hu., et al. [6]. One gram of dried ginger was correctly weighed and extracted with ethanol $(150 \mathrm{ml})$ in a Soxhlet extraction apparatus at $85^{\circ} \mathrm{C}$ for 8 hours. Then the extract was concentrated at less than $85^{\circ} \mathrm{C}$ in a rotary evaporator under vacuum.

Preparation of standards, 6-gingerol, 8-gingerol, 10-gingerol

6-gingerol, 8-gingerol, 10-gingerol were used for preparing the standards followed by [11]. The standard of 6-gingerol, 8-gingerol, and 10-gingerol was used for making standard solutions. Then HPLC-grade methanol was added to prepare a stock standard of 5.0 $\mathrm{mg} / \mathrm{mL}$ for each standard. Different standard solutions were made from the stock solution by dilution with methanol. For determining standard curves, the solutions were prepared to contain 10, 20, 40, 60,80 , and $100 \mathrm{~mL}$, respectively. All the standards of ginger were capped properly with cork and stored at $-20^{\circ} \mathrm{C}$ until used.

\section{HPLC chromatographic analysis}

The ginger extract was analyzed by high-performance liquid chromatography [6]. The ginger extract and standard were analyzed on an HPLC system having a UV detector set at wavelength $280 \mathrm{~nm}$, consist of a C-18 column. The mobile phases with a flow rate of $0.4 \mathrm{~mL} / \mathrm{min}$. and consisted of $0.1 \%$ formic acid in water (A) and acetonitrile (B). The injection volume was set at $2 \mu \mathrm{L}$.

\section{Statistical analysis}

The obtained data were analyzed for all parameters using analysis of variance (ANOVA). Significant differences between samples were analyzed using ANOVA. All the experiments were run in triplicate, and data were reported as the mean \pm standard deviation (SD) as stated by An., et al. [1].

\section{Results and Discussion}

This research was conducted to determine the gingerol contents of dried ginger. Ginger was dried under different treatments i.e. sun drying, oven drying $\left(60^{\circ} \mathrm{C}, 70^{\circ} \mathrm{C}, 80^{\circ} \mathrm{C}\right.$, and $\left.90^{\circ} \mathrm{C}\right)$, microwave drying (100W, 200W, 300W, 450W, 600W, $700 \mathrm{~W}$, and $800 \mathrm{~W}$ ). The main purpose of this study is to find the optimum drying method to preserve maximum gingerol i.e. 6-gingerol, 8-gingerol, 10-gingerol. This research was conducted at the National Institute of Food Science and Technology in collaboration with the Department of Structure and Environmental Engineering, University of 
Agriculture, Faisalabad. The results obtained from the different drying techniques (Sun dring, oven drying, and microwave drying) are presented below in the form of a graph.

\section{Gingerol contents}

The samples of dried ginger powder were subjected to determine gingerol contents i.e. 6-gingerol, 8-gingerol, 10-gingerol, and the results which found statistically and graphically are given below:

\section{6-gingerol}

Comparative evaluation of 6-gingerol of ginger is graphically represented in figure 1 . The value of 6-gingerol content in fresh ginger (Controlled $\mathrm{T}_{0}$ ) was $5.85 \mathrm{mg} / \mathrm{g}$ (mg/g fresh weight $\mathrm{FW}$ ). After drying, the 6-gingerol content was lost due to temperature but the condition in which maximum preserve of 6-gingerol content was oven drying at $70{ }^{\circ} \mathrm{C}\left(\mathrm{T}_{3}\right)$. In this condition $\left(\mathrm{T}_{3}\right)$, the value of 6-gingerol content was $2.61 \mathrm{mg} / \mathrm{g}$ (mg/g Dry weight DW). The 6 -gingerol was also lost in other treatments but the maximum preserve of 6-gingerol content was $\mathrm{T}_{3}$ when compared to other treatments (other than $\mathrm{T}_{3}$ ). The minimum preserve of 6-gingerol was sun drying $\left(\mathrm{T}_{1}\right)$ and microwave drying at $700 \mathrm{~W}\left(\mathrm{~T}_{11}\right)$. In $\mathrm{T}_{1}$ and $\mathrm{T}_{11}$, the value of 6-gingerol content was $1.51 \mathrm{mg} / \mathrm{g}$. The reason for loss of maximum 6-gingerol content in sun drying $\left(\mathrm{T}_{1}\right)$ was longer drying time and in microwave drying at $700 \mathrm{~W}\left(\mathrm{~T}_{11}\right)$ was high power as well as the high temperature of a microwave. The conditions in which the value of the content of 6-gingerol came close to each other were oven drying at $90 \stackrel{\circ}{\circ}\left(\mathrm{T}_{5}\right)$ and microwave at $300 \mathrm{~W}\left(\mathrm{~T}_{8}\right)$. The value of 6-gingerol content was $1.82 \mathrm{mg} / \mathrm{g}$ and $1.83 \mathrm{mg} / \mathrm{g}$ in $\mathrm{T}_{5}$ and $\mathrm{T}_{8}$, respectively.

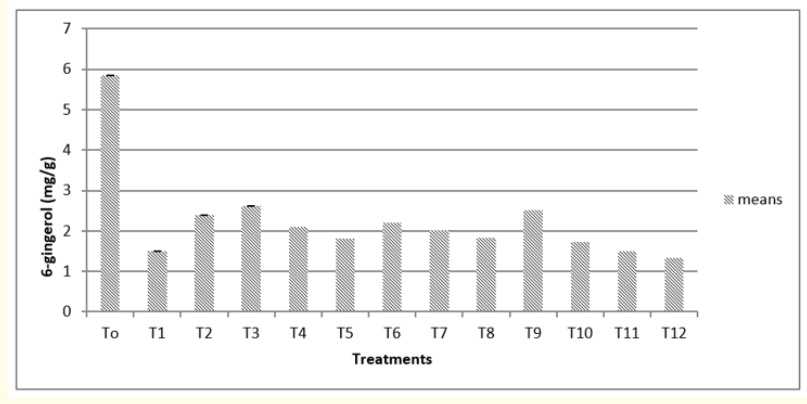

Figure 1: Effect of treatment on 6-gingerol content (mg/g dry weight DW).
An., et al. (2016) also studied the concentration of gingerol content of fresh and dried ginger and found similar results for the 6-gingerol. The quantity of 6-gingerol was $5.91 \mathrm{mg} / \mathrm{g}$ in fresh ginger and $2.50 \mathrm{mg} / \mathrm{g}$ in dried ginger by oven drying. The 6-gingerol content was lessened significantly after drying, particularly in the microwave, only $2.12 \mathrm{mg} / \mathrm{g}$. It can result that a long drying time and the high temperature would increase the reduction of 6-gingerol. The 6-gingerol content was being slightly varied from this study due to some differences in terms and conditions.

\section{8-gingerol}

Comparative evaluation of 8-gingerol of ginger is graphically represented in figure 2. The value of 8-gingerol content in fresh ginger (Controlled $\mathrm{T}_{0}$ ) was $2.6367 \mathrm{mg} / \mathrm{g}(\mathrm{mg} / \mathrm{g}$ fresh weight $\mathrm{FW}$ ). After drying, the 8-gingerol content was lost due to temperature but the condition in which maximum preserve of 8-gingerol content was oven drying at $70{ }^{\circ} \mathrm{C}\left(\mathrm{T}_{3}\right)$. In this condition $\left(\mathrm{T}_{3}\right)$, the value of 8-gingerol content was $2.27 \mathrm{mg} / \mathrm{g}(\mathrm{mg} / \mathrm{g}$ Dry weight DW). The 8-gingerol was also lost in other treatments but the maximum preserve of 8-gingerol content was $\mathrm{T}_{3}$ when compared to other treatments. The minimum preserve of 8-gingerol was sun drying $\left(\mathrm{T}_{1}\right)$ and microwave drying at $800 \mathrm{~W}\left(\mathrm{~T}_{12}\right)$. In $\mathrm{T}_{1}$ and $\mathrm{T}_{12}$, the value of 8-gingerol content were $0.75 \mathrm{mg} / \mathrm{g}$ and $0.8367 \mathrm{mg} / \mathrm{g}$, respectively. The reason for loss of maximum 8-gingerol content in sun drying $\left(\mathrm{T}_{1}\right)$ was longer drying time and in microwave drying at $800 \mathrm{~W}\left(\mathrm{~T}_{12}\right)$ was high power as well as the high temperature of the microwave. The conditions in which the value of the content of 8-gingerol came close to each other were microwave at $600 \mathrm{~W}\left(\mathrm{~T}_{10}\right)$ and $700 \mathrm{~W}\left(\mathrm{~T}_{11}\right)$. The value of 8-gingerol content were $1.0233 \mathrm{mg} / \mathrm{g}$ and $0.9867 \mathrm{mg} / \mathrm{g}$ in $\mathrm{T}_{10}$ and $\mathrm{T}_{11}$, respectively.

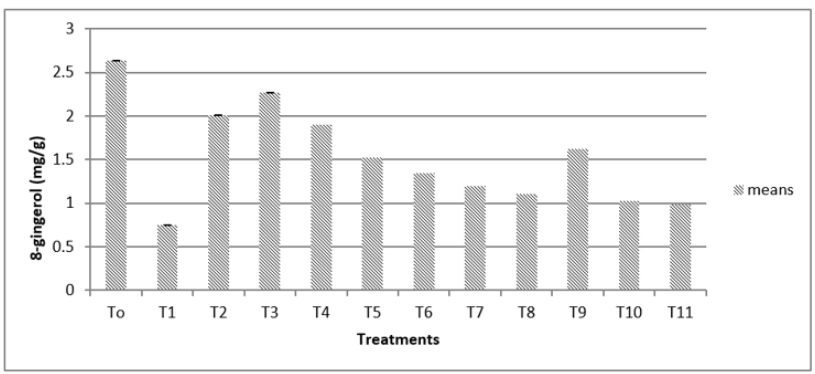

Figure 2: Effects of the different treatments on 8-gingerol content (mg/g dry weight DW). 
An., et al. (2016) also studied the concentration of gingerol content of fresh and dried ginger and found similar results for the 8-gingerol. The quantity of 8-gingerol was $2.52 \mathrm{mg} / \mathrm{g}$ in fresh ginger and $2.43 \mathrm{mg} / \mathrm{g}$ in dried ginger by oven drying. The 8-gingerol content was lessened significantly after drying, particularly in the microwave, only $2.5 \mathrm{mg} / \mathrm{g}$. It can result that a long drying time and the high temperature would increase the reduction of 8-gingerol. The 8-gingerol content was being slightly varied from this study due to some differences in terms and conditions.

\section{0-gingerol}

Comparative evaluation of 10-gingerol of ginger is graphically represented in figure 3 . The value of 10-gingerol content in fresh ginger (Controlled $\mathrm{T}_{0}$ ) was $2.5767 \mathrm{mg} / \mathrm{g}(\mathrm{mg} / \mathrm{g}$ fresh weight $\mathrm{FW}$ ). After drying, the 10-gingerol content was lost due to temperature but the condition in which maximum preserve of 10 -gingerol content was oven drying at $70{ }^{\circ} \mathrm{C}\left(\mathrm{T}_{3}\right)$. In this condition $\left(\mathrm{T}_{3}\right)$, the value of 10 -gingerol content was $2.44 \mathrm{mg} / \mathrm{g}(\mathrm{mg} / \mathrm{g}$ Dry weight DW). The 10-gingerol was also lost in other treatments but the maximum preserve of 10-gingerol content was $\mathrm{T}_{3}$ when compared to other treatments. The minimum preserve of 10 -gingerol was microwave drying at $800 \mathrm{~W}\left(\mathrm{~T}_{12}\right)$. In $\mathrm{T}_{12}$, the value of 10-gingerol content was $0.7433 \mathrm{mg} / \mathrm{g}$. The reason forthe loss of maximum 10-gingerol content in microwave drying at $800 \mathrm{~W}\left(\mathrm{~T}_{12}\right)$ was high power as well as the high temperature of the microwave. The conditions in which the value of the content of 10-gingerol came close to each other were sun drying $\left(\mathrm{T}_{1}\right)$ and microwave at $700 \mathrm{~W}\left(\mathrm{~T}_{11}\right)$. The value of 10 -gingerol content was $0.81 \mathrm{mg} / \mathrm{g}$ both in $\mathrm{T}_{1}$ and $\mathrm{T}_{11}$.

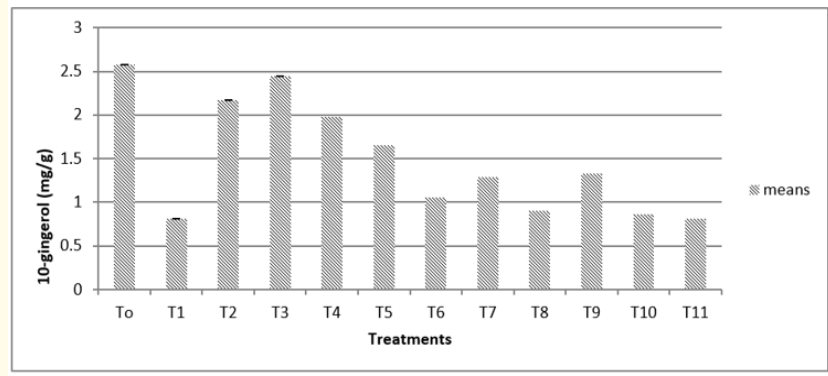

Figure 3: Effects of the different treatment on 10-gingerol content (mg/g dry weight DW).
An., et al. (2016) also studied the concentration of gingerol content of fresh and dried ginger and found similar results for the 10 -gingerol. The quantity of 10 -gingerol was $2.62 \mathrm{mg} / \mathrm{g}$ in fresh ginger and $1.35 \mathrm{mg} / \mathrm{g}$ in dried ginger by oven drying. The 10 -gingerol content was lessened significantly after drying, particularly in the microwave, only $1.05 \mathrm{mg} / \mathrm{g}$. It can result that a long drying time and the high temperature would increase the reduction of 10-gingerol. The 10-gingerol content was being slightly varied from this study due to some differences in terms and conditions.

\section{Conclusion}

Ginger was dried through various drying techniques i.e., sun drying, oven drying, microwave having different treatments. Extraction was done through the Soxhlet extraction method of dried ginger. It was concluded that the optimum drying condition was oven drying at $70^{\circ} \mathrm{C}$ in which maximum gingerol preserve. The quantity of 6-gingerol, 8-gingerol, 10-gingerol were $2.61 \mathrm{mg} / \mathrm{g}$, $2.27 \mathrm{mg} / \mathrm{g}, 2.44 \mathrm{mg} / \mathrm{g}(\mathrm{mg} / \mathrm{g}$ Dry weight DW) respectively at optimum drying condition.

\section{Bibliography}

1. An K., et al. "Comparison of different drying methods on Chinese ginger (Zingiber officinale Roscoe) Changes in volatiles, chemical profile, antioxidant properties, and microstructure". Food Chemistry 197 (2016): 1292-1300.

2. Akdas S and M Başlar. "Dehydration and degradation kinetics of bioactive compounds for mandarin slices under vacuum and oven drying conditions". Journal of Food Processing and Preservation 39 (2015): 1098-1107.

3. Bhattarai S., et al. "The stability of gingerol and shogoal in aqueous solution". Journal of Pharmaceutical Sciences 90 (2011): 1658-1663.

4. Dugasani S., et al. "Comparative antioxidant and anti-inflammatory effects of [6]-gingerol, [8]- gingerol, [10]-gingerol and [6]-shogaol”. Journal of Ethnopharmacology 127 (2010): 515520.

5. Ho SC and MS Su. "Optimized heat treatment enhances the anti-inflammatory capacity of ginger". International Journal of Food Properties 19 (2016): 1884-1898. 
6. Hu J., et al. "Pressurized liquid extraction of ginger (Zingiber officinale Roscoe) with bioethanol: An efficient and sustainable approach". Journal of Chromatography 1218 (2011): 5765-5773.

7. Kamiloglu S., et al. "A review on the effect of drying on antioxidant potential of fruits and vegetables". Critical Reviews in Food Science and Nutrition 56 (2016): 110-129.

8. Motwai TK., et al. "Zingber officinale acts as nutracautical agent against liver fibrosis". Nutrition and Metabolism 8 (2011): 40.

9. Mustafa IB. "Effects of drying methods on antioxidant properties and biological activities of two Malaysian ginger varieties". Journal of the Science of Food and Agriculture (2017): 1-123.

10. Roshanak S., et al. "Evaluation of seven different drying treatments in respect to total flavonoid, phenolic, vitamin C content, chlorophyll, antioxidant activity and color of green tea leaves". Journal of Food Science and Technology 53 (2016): 721-729.

11. Schwertner HA and DC Rios. "High-performance liquid chromatographic analysis of 6-gingerol, 8-gingerol, 10-gingerol, and 6-shogaol in ginger-containingdietary supplements, spices, teas, and beverages". Journal of Chromatography B 856 (2007): 41-47.

12. Sagrin M S and G H Chong. "Effects of drying temperature on the chemical and physical properties of Musa acuminataColla (AAA Group) leaves". Industrial Crops and Products 45 (2013): 430-434.

13. Sivasothy Y., et al. "Essential oils of zingiber officinale var. rubrum theilade and their antibacterial activities". Food Chemistry 124 (2011): 514-517.

14. Tsai TH., et al. "Antioxidant and anti-inflammatory activities of several commonly used compounds". Food Chemistry and Toxicology 70 (2005): 93-97.

15. Yeh H., et al. "Bioactive components analysis of two various gingers and antioxidant effect of ginger extracts". LWT - Food Science and Technology 15 (2013): 1-6.

Volume 5 Issue 7 July 2021

(C) All rights are reserved by Nida Firdous., et al. 